Wymogi Asocjacji Interwencji Sercowo-Naczyniowych Polskiego Towarzystwa Kardiologicznego dla uzyskania tytułu samodzielnego operatora pediatrycznego kardiologii inwazyjnej i akredytacji pediatrycznego ośrodka kardiologii inwazyjnej w Polsce

Stanowisko grupy ekspertów Zarządu Asocjacji Interwencji Sercowo-Naczyniowych Polskiego Towarzystwa Kardiologicznego (PTK) kadencji 2014-2016, zatwierdzone przez Radę Konsultacyjną Asocjacji Interwencji Sercowo-Naczyniowych PTK i Zarząd Główny PTK

\title{
Guidelines of the Association of Cardiovascular Interventions of the Polish Cardiac Society on certification of paediatric invasive cardiology operators and accreditation of paediatric invasive cardiology centres in Poland
}

Tomasz Moszura ${ }^{1}$, Andrzej Ochała ${ }^{2}$, Dariusz Dudek ${ }^{3}$, Jacek Legutko ${ }^{4}$, Jacek Białkowski ${ }^{5}$, Małgorzata Szkutnik ${ }^{5}$, Radosław Parma ${ }^{2}$, Zbigniew Chmielak ${ }^{6}$, Stanisław Bartuś ${ }^{4}$, Marek Grygier ${ }^{7}$, Tomasz Pawłowski ${ }^{8}$, Sławomir Dobrzycki ${ }^{9}$, Zbigniew Kalarus ${ }^{10}$

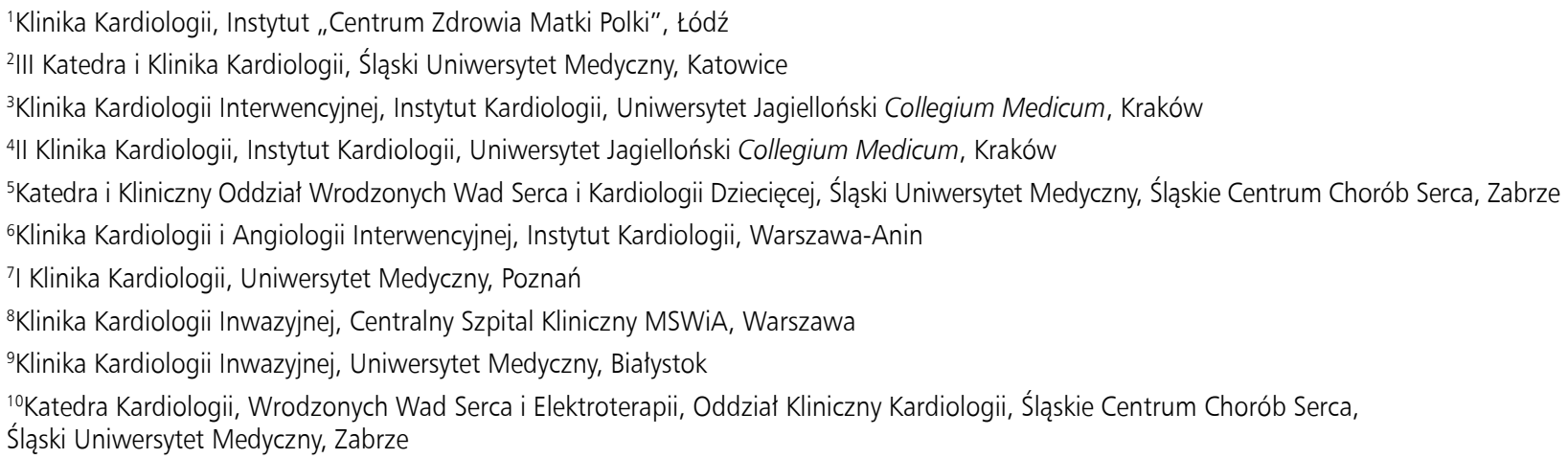

\section{WSTĘP}

Zmiany w organizacji pediatrycznych ośrodków kardiologii inwazyjnej i wymogi Narodowego Funduszu Zdrowia w zakresie warunków niezbędnych do realizacji świadczeń refundowanych ze środków publicznych oraz wdrażanie systemu kontroli jakości w pediatrycznej kardiologii inwazyjnej stwarzają potrzebę opracowania jednolitych wymogów niezbędnych do uzyskania uprawnień samodzielnego operatora pediatrycznego kardiologii inwazyjnej i akredytacji pediatrycznych pracowni kardiologii inwazyjnej.

Zarząd Asocjacji Interwencji Sercowo-Naczyniowych Polskiego Towarzystwa Kardiologicznego (AISN PTK) i Zarząd Główny Polskiego Towarzystwa Kardiologicznego (PTK) poddały dyskusji i przyjęły następujące zasady certyfikacji 
samodzielnych pediatrycznych operatorów kardiologii inwazyjnej oraz akredytacji pediatrycznych ośrodków kardiologii inwazyjnej w Polsce.

\section{WYMOGI NIEZBĘDNE DO UZYSKANIA UPRAWNIEŃ SAMODZIELNEGO OPERATORA PEDIATRYCZNEGO KARDIOLOGII INWAZYJNEJ}

Za pediatryczną kardiologię inwazyjną uznaje się wiedzę i umiejętności praktyczne pozwalające na wykonywanie diagnostycznych cewnikowań serca i przezskórnych zabiegów terapeutycznych, tzw. zabiegów interwencyjnych u pacjentów z wadami wrodzonymi i chorobami serca w wieku 0-18 lat. Stanowią także podstawę do wykonywania tych zabiegów u dorosłych pacjentów z wrodzonymi i strukturalnymi wadami serca.

1. Tytuł samodzielnego operatora w zakresie dziecięcej kardiologii inwazyjnej może otrzymać lekarz ze specjalizacją z kardiologii dziecięcej, pediatra-kardiolog lub kardiolog będący członkiem AISN PTK.

2. Podstawowe szkolenie powinno być prowadzone pod kontrolą kierownika szkolącej pracowni, która uzyskała klasę B wg standardów akredytacyjnych AISN PTK.

3. W danym ośrodku na jednego szkolącego się powinien przypadać co najmniej jeden samodzielny operator pediatrycznej kardiologii inwazyjnej.

4. Czas szkolenia wynosi 18 miesięcy; w tym okresie lekarz musi wykonać osobiście (pod nadzorem) co najmniej 75 (50/rok) podstawowych przezskórnych zabiegów terapeutycznych, tzw. kardiologicznych zabiegów interwencyjnych u chorych w wieku 0-18 lat lub starszych pacjentów z wrodzonymi wadami serca. Zaświadczenie o ukończeniu szkolenia wystawia kierownik pracowni szkolącej.

5. Podczas szkolenia wymagane jest zgromadzenie minimum 30 punktów za uczestnictwo w kongresach kardiologii inwazyjnej rekomendowanych przez AISN PTK (Załącznik 1)

6. Po spełnieniu powyższych warunków zainteresowany składa pisemny wniosek o przyznanie certyfikatu do Przewodniczącego AISN PTK.

a. Do wniosku muszą być dołączone zaświadczenia potwierdzające spełnienie wszystkich poniższych wymogów:

- kopia dyplomu specjalizacji;

- zaświadczenie o liczbie przeprowadzonych zabiegów w formie „oświadczam wykonanie... zabiegów";

- kopie certyfikatów uczestnictwa w kongresach (wg Załącznika 1);

- aktualne zaświadczenie o członkostwie w PTK.

b. Podania powinny wpływać na adres aktualnej siedziby AISN PTK.

c. O certyfikat występuje kierownik pracowni hemodynamiki lub dwóch kardiologów z poparciem dla ubiegającego się.
7. Certyfikat samodzielnego operatora jest sygnowany przez Przewodniczącego AISN PTK oraz Prezesa PTK i jest ważny 3 lata (wzór certyfikatu: Załącznik 2).

8. W celu przedłużenia certyfikatu na kolejne 3 lata konieczne jest wykonanie co najmniej 150 zabiegów terapeutycznych w ciągu 3 lat.

9. Od dnia 1 stycznia 2013 r. wykonanie zabiegów musi być potwierdzone w książce zabiegowej oraz w bazie danych AISN PTK. Jeśli lekarz wykonał osobiście (pod nadzorem) zabiegi w ośrodkach zagranicznych, powinien przedstawić zaświadczenie o liczbie i rodzaju wykonanych zabiegów podpisane przez kierownika pracowni.

10. Jeśli operator wykonał $w$ ciągu ostatnich 3 lat ponad 250 zabiegów interwencyjnych, w celu uzyskania przedłużenia certyfikatu nie musi przedkładać zaświadczeń o liczbie przeprowadzanych zabiegów, a jedynie uzyskać co najmniej 20 punktów rocznie.

11. Dotychczasowe certyfikaty tracą ważność 30 czerwca 2014 r.

12. Zgodnie z uchwałą Zarządu AISN PTK certyfikaty operatorów pediatrycznych kardiologii inwazyjnej są zwolnione z opłaty.

\section{ZASADY WPISU DO REJESTRU} PEDIATRYCZNYCH PRACOWNI KARDIOLOGII INWAZYJNEJ AKREDYTOWANYCH PRZEZ PTK

1. Nadanie akredytacji służy zapewnieniu wysokiej jakości i bezpieczeństwa zabiegów wykonywanych w pediatrycznych pracowniach kardiologii inwazyjnej.

2. Akredytacje są nadawane przez Zarząd Główny PTK na wniosek Zarządu AISN PTK, który opiniuje wnioski (wzór certyfikatu: Załącznik 3).

3. Akredytacja jest przyznawana każdorazowo na 3 lata. Po tym okresie należy ponownie złożyć wniosek o przedłużenie/zmianę akredytacji.

4. Możliwe jest wcześniejsze złożenie wniosku o podwyższenie klasy akredytacji, jeżeli dana pracownia spełniła wszystkie wymagane dla wyższej klasy akredytacji kryteria.

5. Posiadanie akredytacji jest tożsame z poświadczeniem o wypełnianiu przez ośrodek bazy danych zabiegów kardiologii inwazyjnej AISN PTK.

6. Pediatryczne pracownie kardiologii inwazyjnej powinny być zlokalizowane jedynie w referencyjnych ośrodkach kardiologicznej opieki pediatrycznej (24-godzinne zabezpieczenie oddziału kardiologii dziecięcej, pediatrycznego oddziału intensywnej opieki medycznej, oddziału kardiochirurgii dziecięcej i pracowni hemodynamiki).

7. Zakres działalności pediatrycznych pracowni kardiologii inwazyjnej obejmuje wszystkie zabiegi z zakresu inwazyjnej diagnostyki kardiologicznej:

a. diagnostyczne cewnikowanie serca w wadach wrodzonych; 
b. diagnostyczne cewnikowanie serca w wadach nabytych;

c. biopsje mięśnia sercowego;

d. interwencyjne zabiegi kardiologiczne w wadach wrodzonych serca (w tym zabiegi ratujące życie) w zakresie zabiegów standardowych:

- przeznaczyniowe atrioseptostomie;

- walwuloplastyki balonowe;

- angioplastyki balonowe;

— zamykanie przetrwałego przewodu tętniczego;

- zamykanie innych nieprawidłowych naczyń;

— zamykanie ubytku przegrody międzyprzedsionkowej;

e. w niektórych pracowniach są wykonywane dodatkowo interwencyjne zabiegi ponadstandardowe, które wydzielono ze względu na ich małą liczbę i stopień trudności:

- przeznaczyniowe lub hybrydowe (przez torakotomię) zamykanie ubytków przegrody międzykomorowej;

- implantacje stentów do dużych naczyń;

- wszczepianie zastawek na stencie;

- implantacje stentów do przewodu tętniczego u noworodków;

- udrażnianie zarośniętej zastawki płucnej u noworodków;

- inne wykraczające poza wykaz procedur standardowych.

8. W zależności od spełnienia poniższych kryteriów pracownia uzyskuje jedną z dwóch klas akredytacji: A lub B.

9. Wymogi kwalifikacyjne dla pediatrycznej pracowni kardiologii inwazyjnej klasy A i B.

a. Wyposażenie:

— angiograf cyfrowy wysokiej klasy z oprogramowaniem umożliwiającym wykonywanie pomiarów struktur anatomicznych, pomiarów parametrów czynnościowych lewej komory i archiwizację danych;

- strzykawka automatyczna;

- aparatura rejestrująca stan hemodynamiczny pacjenta;

- hemoksymetr;

- aparat do znieczulenia z możliwością monitorowania funkcji życiowych pacjenta;

- defibrylator i kardiostymulator zewnętrzny;

- pełen zestaw specjalistycznego sprzętu medycznego służącego do wykonywania diagnostycznych zabiegów kardiologicznych u dzieci i standardowych zabiegów interwencyjnych (w przypadku pracowni klasy B również sprzęt wymagany do przeprowadzania zabiegów ponadstandardowych).

b. Personel:

- kierownik pediatrycznej pracowni kardiologii inwazyjnej/kierownik programu inwazyjnej kardiologii dziecięcej (dotyczy pracowni użytkowanych wspólnie z kardiologami lub radiologami interwencyjnymi);

- specjalista kardiolog dziecięcy lub pediatra-kardiolog.

c. Minimalna liczba procedur w ciągu roku:

— pracownie klasy A — zabiegi kardiologii interwencyjnej: 50;

- pracownie klasy B — zabiegi kardiologii interwencyjnej: 100.

10. Wniosek akredytacyjny składa kierownik pracowni, dołączając oświadczenie potwierdzające spełnienie stosownych wymogów. Przesłane dane są następnie weryfikowane w Ogólnopolskiej Bazie Danych AISN PTK.

11. Koszt wydania certyfikatu akredytacji wraz z zaświadczeniem o wypełnianiu przez ośrodek bazy danych zabiegów kardiologii inwazyjnej AISN PTK wynosi łącznie 3000 PLN.

Konflikt interesów: Zbigniew Kalarus - wykłady dla firm: Pfizer, Eli Lilly, Boehringer-Ingelheim, Abbott, Bayer; wyjazdy na kongresy kardiologiczne: St. J. Medical, Adamed; komitet doradczy: Boehringer-Ingelheim, Amgen.

Załącznik 1. Punktacja za uczestnictwo w kongresach kardiologicznych

1. Międzynarodowy Kongres Polskiego Towarzystwa Kardiologicznego (PTK) - 20 pkt.

2. Ogólnopolska Konferencja Sekcji Kardiologii Dziecięcej PTK - 20 pkt.

3. Zjazd Europejskiego Towarzystwa Kardiologii Dziecięcej (AEPC) - 20 pkt.

4. Warsztaty interwencyjne PICS \& AICS (zabiegi u dorosłych i dzieci z wrodzonymi wadami serca w Stanach Zjednoczonych) - 20 pkt.

5. Warsztaty Kardiologii Interwencyjnej we Frankfurcie i Mediolanie (u dorosłych i dzieci z wrodzonymi wadami serca) - 20 pkt.

6. Światowy Kongres Kardiologii Dziecięcej (co 4 lata) - 20 pkt.

7. Inne szkolenia krajowe, które uzyskają akredytację AISN PTK. 
Załącznik 2. Wzór certyfikatu samodzielnego operatora pediatrycznego kardiologii inwazyjnej

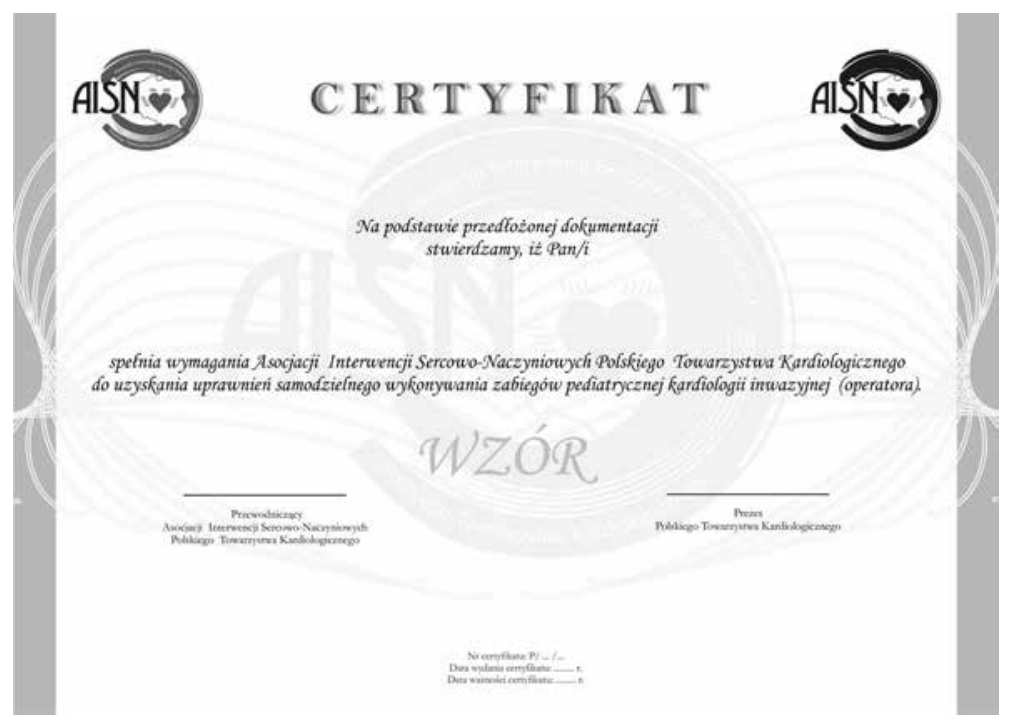

Załącznik 3. Wzór certyfikatu akredytacji pediatrycznej pracowni kardiologii inwazyjnej

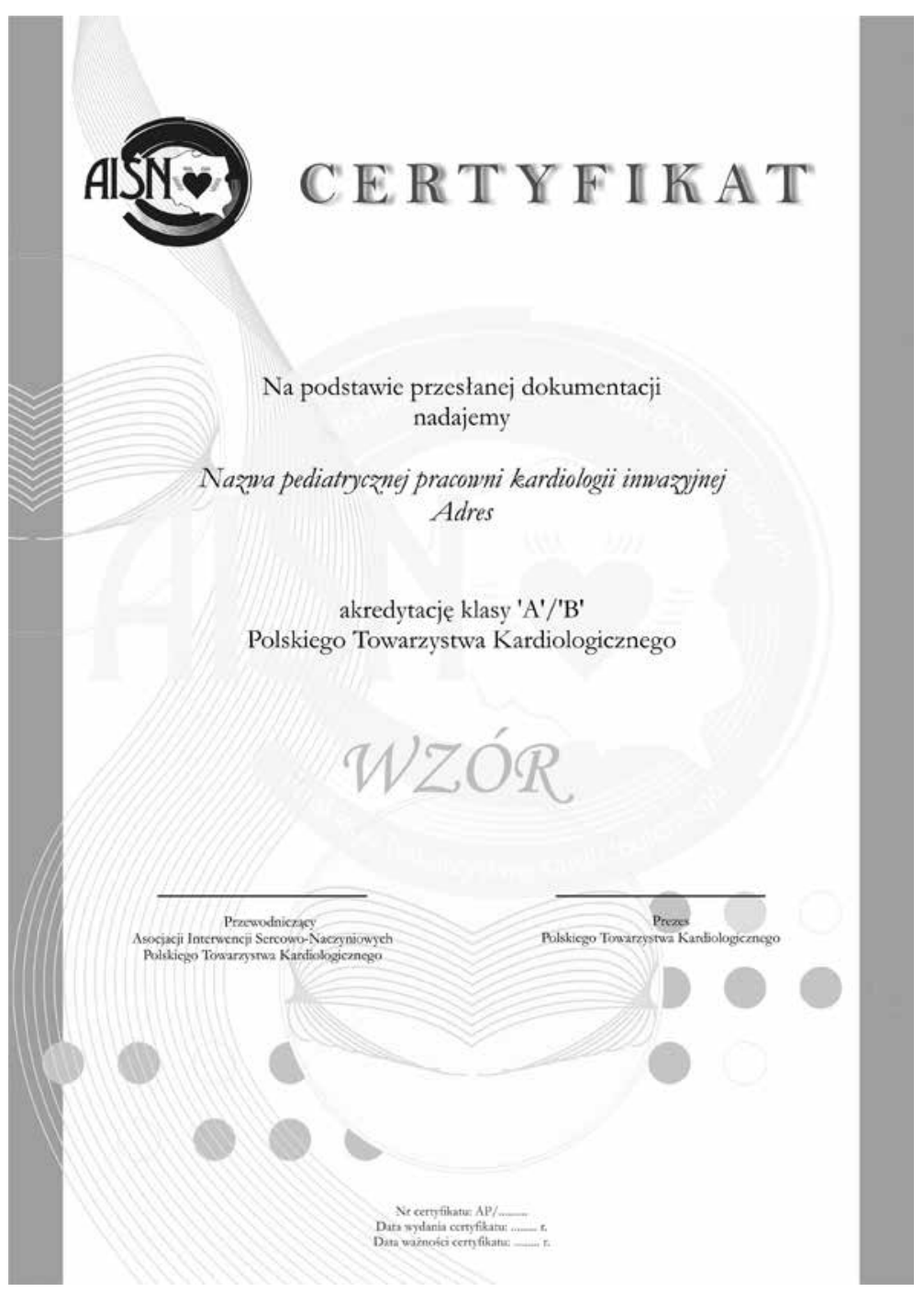

